\title{
GABA and Bicuculline Actions on Mouse Spinal Cord and Cortical Neurons in Cell Culture
}

\author{
LINDA M. NOWAK, ANNE B. YOUNG and ROBERT L. MACDONALD
}

Neurosciences Program and (A.B.Y. and R.L.M.) Department of Neurology, University of Michigan, Ann Arbor, MI 48109 (U.S.A.)

(Accepted December 24th, 1981)

Key words: GABA - bicuculline - spinal cord - cortex - cell culture

\begin{abstract}
The neutral amino acid $\gamma$-aminobutyric acid (GABA) produced membrane hyperpolarization and increased membrane chloride ion conductance of spinal cord (SC) and cortical (CTX) neurons in cell culture. GABA dose-response curves were obtained for SC neurons by pressure applying known concentrations of GABA from micropipettes with large tips (miniperfusion pipettes). GABA response threshold was about $2 \mu \mathrm{M}$ and large responses were elicited at GABA concentrations greater than $10 \mu \mathrm{M}$. Bicuculline (BICUC) $(0.1-10 \mu \mathrm{M})$ reversibly antagonized GABA responses on both SC and CTX neurons with a half maximal inhibitory concentration of about $1 \mu \mathrm{M}$. BICUC antagonism of GABA responses was competitive (Lineweaver-Burke analysis). These results are compared with data on GABA and BICUC displacement of $\left[{ }^{3} \mathrm{H}\right] \mathrm{GABA}$ binding 10 membranes of SC and CTX neurons in cell culture. It is suggested that high affinity GABA receptors are likely to be relevant for postsynaptic GABA responses while low affinity GABA receptors may be presynaptic.
\end{abstract}

\section{INTRODUCTION}

The neutral amino acid $\gamma$-aminobutyric acid (GABA) has a widespread distribution in the central nervous system ${ }^{9,24,38}$ and is a neurotransmitter mediating both pre $^{25}$. and postsynaptic inhibition ${ }^{23}$. GABA interacts with receptors on neuronal membranes to increase chloride ion conductance and thus to displace membrane potential toward the chloride equilibrium potential ${ }^{8,30,31}$. Using [ $\left.{ }^{3} \mathrm{H}\right]$ GABA, GABA has been demonstrated to bind to both high and low affinity receptors on brain membranes ${ }^{13,18,48}$. The relationship between GABAbinding and GABA-physiology, however, is uncertain. For example, are low or high affinity GABA receptors the physiologically relevant receptors for GABA-mediated postsynaptic inhibition, and which receptors are relevant for GABA-mediated presynaptic inhibition?

Bicuculline is a phthalide-isoquinoline alkaloid which antagonizes GABA-mediated inhibition ${ }^{5-7,21}$ by binding $t^{29}$ and displacing GABA from ${ }^{12,33,49}$ $\mathrm{GABA}$ receptors and produces convulsions when administered systemically or applied topically to cortex ${ }^{21,35,46}$. Bicuculline has been shown to antagonize GABA responses in central nervous system ${ }^{6,7}$, in spinal cord ${ }^{5}$, on dorsal root ganglion neurons ${ }^{10}$, $14,16,31$, on invertebrate neurons ${ }^{34}$ and on muscle ${ }^{39}$. 41,42 . In most preparations where specificity could be studied, bicuculline antagonized only GABA responses and did not alter responses to other amino acids including glycine, $\beta$-alanine or glutamate ${ }^{6,7}$, 26. Bicuculline antagonized GABA responses at concentrations that did not alter either resting membrane potential or membrane conductance ${ }^{19}$. These findings have suggested that bicuculline interacts specifically with GABA receptors.

On spinal cord ${ }^{2,36}$ and cortical neurons ${ }^{11}$ in primary dissociated cell culture, GABA also produces inhibition by increasing chloride ion conductance and producing membrane hyperpolarization. In addition, specific antagonism of GABA responses is produced by bicuculline $11,19,26$. In a companion paper, we have demonstrated that saturable, sodium-independent binding of $\left[{ }^{3} \mathrm{H}\right] \mathrm{GABA}$ and $\left[{ }^{3} \mathrm{H}\right]$ muscimol (a GABA agonist) is present in mem- 
branes from mouse neurons in cell culture with binding characteristics similar to those of membranes from adult rat brain ${ }^{15}$. Thus, spinal cord and cortical neurons in cell culture provide preparations in which neurochemical and electrophysiological data can be directly compared.

In this paper we present the dose-dependency of GABA responses and of antagonism of GABA responses by bicuculline. We will compare these results to data presented in a companion paper $^{15}$ using $\left[{ }^{3} \mathrm{H}\right] \mathrm{GABA}$ binding and its antagonism by bicuculline to membranes from spinal cord and cortical neurons in cell culture.

\section{MATERIALS AND METHODS}

\section{Primary dissociated cell culture}

Dissociated neuronal cell cultures were prepared from spinal cords with attached dorsal root ganglia and cortices dissected from 12 to 14-day-old and 15 to 16-day-old mouse embryos respectively as described previously ${ }^{37}$. The cultures were then maintained for 4-12 weeks prior to electrophysiological experiments.

\section{Intracellular recording}

Visually guided penetration of spinal cord and cortical neurons was accomplished on the modified stage of an inverted phase-contrast microscope with controlled temperature $\left(35-37^{\circ} \mathrm{C}\right)$. Spinal cord neurons were distinguished from dorsal root ganglion neurons by appearance and identification was confirmed electrophysiologically. Intracellular recordings were made with high impedance (spinal cord neurons, 25-40 M $\Omega$; cortical neurons, 55-70 M $\Omega$ ) glass micropipettes filled with $4 \mathrm{M}$ potassium acetate (KAc) or $3 \mathrm{M}$ potassium chloride $(\mathrm{KCl})$. Simultaneous current injection and membrane potential measurements with single recording microelectrodes were permitted by using a conventional bridge circuit and data were recorded on a 6-channel Brush polygraph or on film by a Grass camera. Recordings were made from neurons bathed in Dulbecco's phosphate buffered saline (DPBS; Gibco, Grand Island, NY) with $10 \mathrm{mM} \mathrm{Mg}^{2+}$ and $1 \%$ glucose. The $\mathrm{pH}$ was 7.2-7.4.

\section{Iontophoresis}

Iontophoretic application of GABA (Sigma, St.
Louis, $\mathrm{MO}$ ) to neurons during intracellular recording was performed in $10 \mathrm{mM} \mathrm{Mg} \mathrm{Mg}^{2} /$ DPS medium which suppressed spontaneous synaptic activity GABA ( $0.5 \mathrm{M}$; pH 1.3 or 3.3$)$ was applied iontophoretically from individual micropipettes (50-100 M $\Omega$ ) using a constant current stimulator. Brief (50-250 ms) rectangular current pulses (0 to $+34 \mathrm{nA}$ ) were used to apply GABA within $2 \mu \mathrm{m}$ of the neuronal soma membrane preceding, during, and after mini-perfusion of the cell with bicuculline or control medium. Intracellular recordings were made with $\mathrm{KCl}$-containing micropipettes resulting in an increase in intracellular chloride ions and a change of the reversal potential for GABA from $60 \mathrm{mV}$ to about $-20 \mathrm{mV}$. Injection of steady constant current through the $\mathrm{KCl}$ recording micropipette was used to hyperpolarize the cell membrane to -70 to $-90 \mathrm{mV}$ and thus $\mathrm{GABA}$ responses were depolarizing.

\section{Miniperfusion}

Miniperfusion was lised to locally superfuse neurons with solutions of known concentration. Miniperfusion was achieved by delivering a pressure pulse to the open shank end $(0.9 \mathrm{~mm}$ lumen diameter) of a fluid-filled glass micropipette whose tip was large (2-10 $\mu \mathrm{m}$ diameter). A voltage-activated. 3-way pressure valve was controlled by an electronic timer. Air pressure to the valve $\left(1-3.5 \mathrm{lbs} / \mathrm{in} .{ }^{2}\right)$ was governed by a pressure regulator. When the valve was closed, the miniperfusion pipette was at atmospheric pressure. Pipettes were checked at the beginning of experiments by bringing the pipette tip up against a small neuronal soma in the culture plate on the recording stage of the microscope and observing cell movement during 1-2 s pressure pulses. During intracellular recording, miniperfusion pipettes were positioned $15-100 \mu \mathrm{m}$ from the soma depending upon the size of their tips. A membrane hyperpolarization, the amplitude of which was pressure-dependent, occurred during fluid ejection with both $\mathrm{KAc}$ and $\mathrm{KCl}$ recordings for both drug and control solutions. Although this hyperpolarization could be eliminated by decreasing the line pressure, or by moving the pipette further from the soma, a small hyperpolarizing artifact was retained often as assurance of miniperfusion.

Miniperfusion of bicuculline was combined with 
iontophoresis of GABA. The tip of a GABA iontophoretic pipette was positioned adjacent to a spinal cord neuron after a stable intracellular recording was obtained. GABA was applied at intervals of 2-5 s and iontophoretic current was adjusted to obtain GABA responses of about $10-20 \mathrm{mV}$. The tip of a bicuculline-containing miniperfusion pipette was then positioned $10-50 \mu \mathrm{m}$ from the tip of the iontophoretic pipette. If the GABA response was reduced when the bicuculline-containing pipette was positioned (an indication of a 'leaking' pipette), the bicuculline-containing pipette was replaced. Care was taken not to direct the miniperfusion pipettes directly at the tip of the amino acid iontophoretic pipettes so the depolarizations produced by these substances were not attenuated by bulk flow from the perfusing pipettes. Control medium or two different concentrations of drug were used in each miniperfusion experiment and dose-dependency was taken as further evidence against a bulk flow effect. Bicuculline concentration was undoubtedly reduced by dilution in the recording medium surrounding the cell during miniperfusion, and therefore the concentration in the pipette was taken as the upper limit of the dose actually at the cell membrane. Long duration (5-15 s) pressure pulses were used.

Bicuculline was dissolved in $0.02 \mathrm{~N} \mathrm{HCl}$ at the beginning of each experiment and dilutions were made with the DPBS control medium described. The $\mathrm{pH}$ of more concentrated bicuculline solutions was adjusted with $\mathrm{NaOH}$ when necessary, and all bicuculline solutions were stored at $8{ }^{\circ} \mathrm{C}$ in light proof containers prior to use. All data were obtained within $2 \mathrm{~h}$ of preparation of bicuculline-containing solutions at neutral $\mathrm{pH}$ since bicuculline is unstable at neutral $\mathrm{pH}^{32}$.

\section{Superfusion}

Bicuculline was also applied by superfusion of the culture plate. After a stable intracellular recording was obtained, the tip of a GABA iontophoretic pipette was positioned adjacent to the spinal cord neuron and current was adjusted to achieve a response of about $10-20 \mathrm{mV}$. Superfusion of control medium at $0.3-0.5 \mathrm{cc} / \mathrm{min}$ was then started. If no alteration in GABA response occurred, the culture was superfused by a bicuculline-containing solution and superfusion was continued until the GABA responses were reduced to a stable level (defined as 3 consecutive equal responses). The superfusion medium was then returned to control. With this technique, up to 10 changes with 5 different bicuculline concentrations could be applied to a single cell. Reduction of GABA responses by bicuculline was accepted for analysis only if the response returned to control levels after the bicuculline was replaced by control medium.

\section{Analysis of dose-response data}

GABA dose-response curves were obtained by varying the amplitudes of constant duration iontophoretic pulses of GABA. Log-log plots of such dose response data were also made so that the limiting $\log \log$ slope at low iontophoretic currents could be measured. The effect of bicuculline on GABA dosedependency was determined by obtaining control dose-response data and then superfusing the dish with a bicuculline-containing solution. During superfusion, GABA was applied using a constant iontophoretic current. When the GABA response reached a steady reduced value due to bicuculline addition, another GABA dose-response curve was obtained. The bicuculline was then replaced by control medium and dose-response data were again obtained. Data were only accepted if the GABA responses recovered to control values following washout of bicuculline. Lineweaver-Burke plots of the dose-response data were then made to determine the nature of the antagonism of GABA responses by bicuculline.

The dose-dependency of the bicuculline antagonism of GABA responses was studied by obtaining a control GABA response of $10-20 \mathrm{mV}$ amplitude and then superfusing the culture with several different concentrations of bicuculline. Bicuculline was generally added from lowest to highest concentration. Data were accepted only if the GABA responses returned to control values following superfusion with control medium.

\section{RESULTS}

GABA hyperpolarized spinal cord and cortical neurons and increased membrane chloride ion conductance

When GABA was applied by miniperfusion to spinal cord (Fig. 1 $\mathrm{A}_{1}$ ) and cortical neurons, mem- 
brane hyperpolarization and an increase in conductance were produced. Short periods of GABA application ( $1-2 \mathrm{~s}$ ) produced responses $10-15 \mathrm{~s}$ in duration. If the recording micropipette contained $3 \mathrm{M}$ $\mathrm{KCl}$ rather than $4 \mathrm{M} \mathrm{KAc}$, chloride ions entered the neuron changing the equilibrium potential for chloride ion from about $-65 \mathrm{mV}$ to $-20 \mathrm{mV}^{2}$, and the GABA responses became depolarizing (Fig. $1 \mathrm{~A}_{2}$ ). GABA was also applied to spinal cord and cortical neurons using iontophoresis (Fig. 1B) with $200 \mathrm{~ms}$ pulses producing $400-500 \mathrm{~ms}$ depolarizing responses (3 $\mathrm{M} \mathrm{KCl-filled} \mathrm{recording} \mathrm{micropipettes).}$

The dose-dependency of GABA responses was studied in spinal cord neurons using miniperfusion of GABA and recording with $3 \mathrm{M} \mathrm{KCl-containing}$ micropipettes. In each experiment, 3 miniperfusion pipettes were used, each containing a different concentration of GABA. The cell was impaled by the recording micropipette and hyperpolarized to between -70 and $-80 \mathrm{mV}$. The tip of a single miniperfusion pipette was then brought up to within one cell body $(20-40 \mu \mathrm{m})$ of the neuron, and GABA was applied for $1 \mathrm{~s}$. The amplitude of the GABA responses recorded using 1-10 $\mu \mathrm{M} \mathrm{GABA}$ were averaged and plotted (Fig. 2). Threshold for GABA responses was about $2 \mu \mathrm{M}$ and large $(>20 \mathrm{mV}$ )

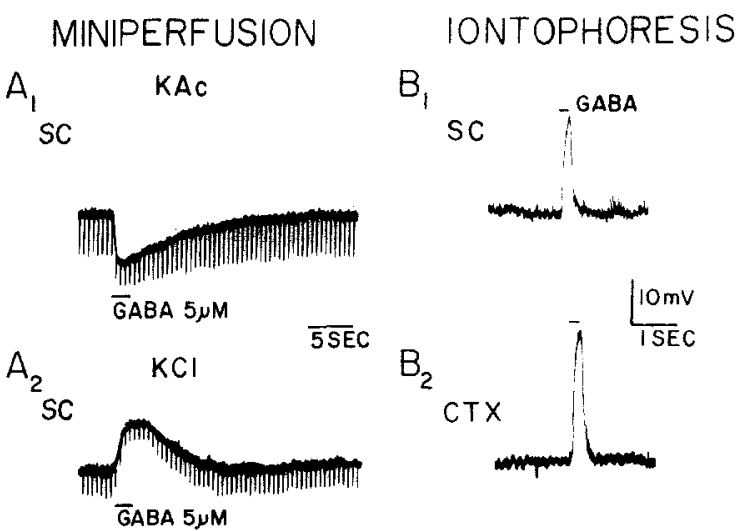

Fig. 1. $\gamma$-Aminobutyric acid (GABA) responses of spinal cord (SC) and cortical (CTX) neurons. A: miniperfusion of SC neurons with $5 \mu \mathrm{M}$ GABA increased membrane conductance and evoked hyperpolarizing responses during recordings with (A1) $4 \mathrm{M} \mathrm{KAc}$-filled and depolarizing responses with $\left(\mathrm{A}_{2}\right) 3 \mathrm{M}$ $\mathrm{KCl}$-filled intracellular micropipettes. Resting membrane potentials (RMPs) were $-44 \mathrm{mV}$ and $-46 \mathrm{mV}$ respectively. B: iontophoretic application of GABA evoked depolarizing responses from $\mathrm{SC}\left(\mathrm{B}_{1}\right)$ and $\mathrm{CTX}\left(\mathrm{B}_{2}\right)$ neurons during recordings with $\mathrm{KCl}$-filled micropipettes. MPs were $-90 \mathrm{mV}$. GABA was applied with $200 \mathrm{~ms}$ pulses of $3.8 \mathrm{nA}\left(\mathrm{B}_{1}\right)$ and 9.0 $n A\left(B_{2}\right)$.

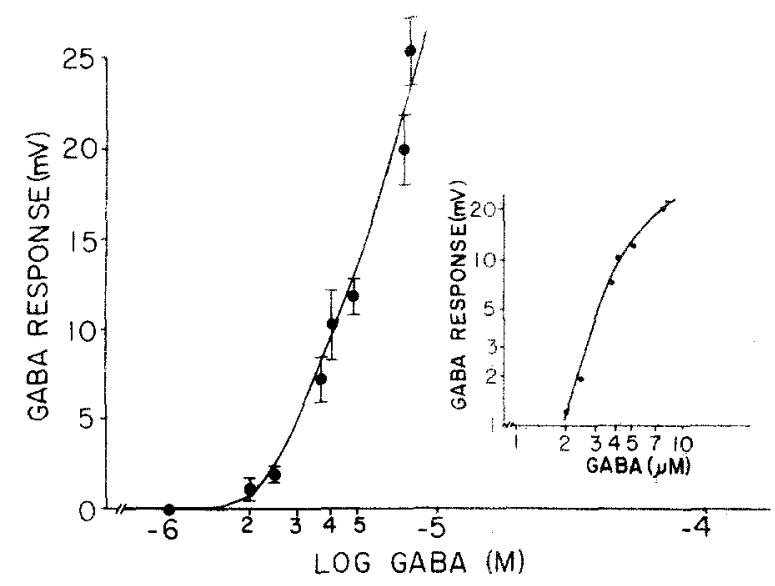

Fig. 2. GABA responses were dose-dependent. Miniperfusion of SC neurons ( $\mathrm{n}=13$ cells) with $1-10 \mu \mathrm{M}$ GABA evoked dosedependent GABA responses with threshold between 1 and $2 \mu \mathrm{M}$. Responses at each concentration are averages of responses on 3-5 cells (6-13 trials). Bars indicate $t$ the standard error of the mean (S.E.M.). Log GABA response vs log GABA concentration is plotted in inset. See text for further details.

responses could be obtained at $10 \mu \mathrm{M}$. Log-log plot of the dose-response data (inset Fig. 2) was linear at low GABA concentrations $(<4 \mu \mathrm{M})$ but deviated toward the abscissa at higher concentrations. The slope of the linear portion of the log-log plot was 2.8 .

\section{Bicuculline antagonized $G A B A$ responses}

Bicuculline rapidly and reversibly reduced the amplitude of iontophoretic GABA responses on spinal cord and cortical neurons (Fig. 3). In spinal cord neurons, bicuculline was applied locally by miniperfusion as well as by bath superfusion, while in cortical neurons only miniperfusion was used. Results obtained using mini-perfusion of bicuculline were similar to those obtained with superfusion of bicuculline if small tipped (10-20 $\mu \mathrm{m})$ miniperfusion pipettes were used. If larger tips were used, small (10-20\%) artifactual reductions of GABA-responses were produced.

Bicuculline had no effect on either resting membrane potential or membrane resistance at the concentrations used in this study $(<10 \mu \mathrm{M})$. However, at higher concentrations $(>10 \mu \mathrm{M})$, bicuculline produced membrane depolarization with an increase in membrane resistance (not illustrated) ${ }^{19}$. 

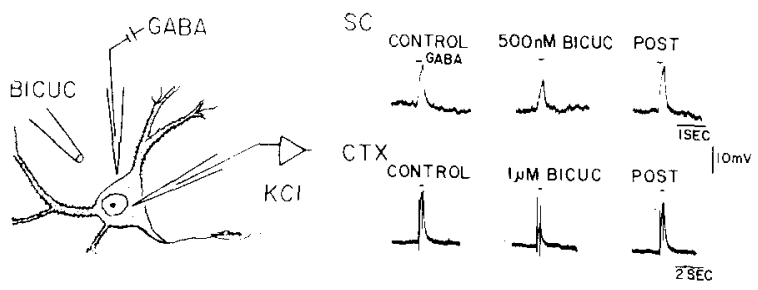

Fig. 3. Bicuculline (BICUC) decreased GABA-responses. The scheme on the left shows the experimental paradigm. The data traces at the right show that iontophoresis of GABA evoked depolarizing responses from $\mathrm{SC}$ (upper traces) and CTX (lower traces) neurons and that application of $500 \mathrm{nM}$ and $1 \mu \mathrm{M}$ BICUC decreased the GABA responses. GABA was delivered by $200 \mathrm{~ms}$ constant current pulses of $4 \mathrm{nA}$ to SC cells and $34 \mathrm{nA}$ to CTX cells. Membrane potential was increased to $-94 \mathrm{mV}(\mathrm{SC})$ and $-72 \mathrm{mV}$ (CTX) by passing hyperpolarizing current through the $3 \mathrm{M} \mathrm{KCl}$-filled recording pipette.

Bicuculline reduced the amplitude of GABA responses but did not alter the time course of the responses. The time courses of GABA responses produced by iontophoresis under control conditions and following superperfusion of $0.5,1$ and $2 \mu \mathrm{M}$ bicuculline (Fig. 4) are plotted semilogarithmically. In all cases the GABA responses decayed exponentially with the same time constant (the decay curves are parallel despite each GABA response having a different amplitude).

Antagonism of GABA responses by bicuculline was dose-dependent in both spinal cord and cortical neurons (Fig. 5). In spinal cord neurons (filled triangles), the threshold for antagonism of GABA

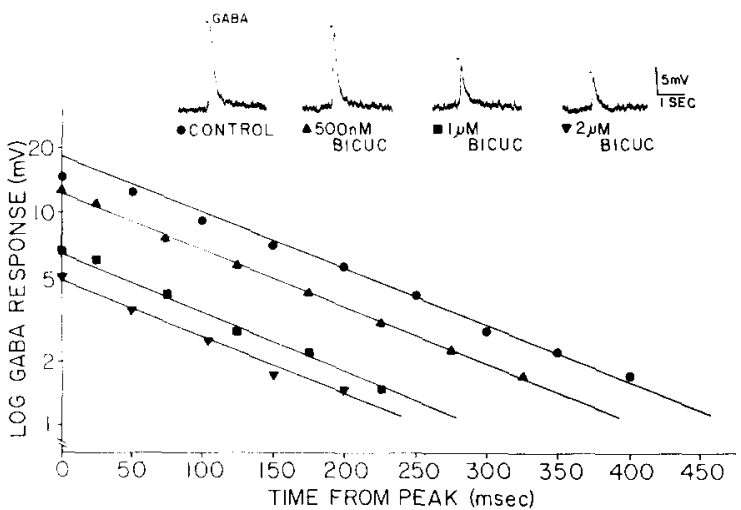

Fig. 4. BICUC reduced GABA response amplitude without changing response kinetics. GABA response amplitude $(\mathrm{mV})$ from the peak response was plotted as a function of time (ms) during superfusion of $0,0.5,1.0$ and $2.0 \mu \mathrm{M}$ BICUC. GABA responses were evoked by $50 \mathrm{~ms}, 10 \mathrm{nA}$ current pulses. Membrane potential was increased to $-78 \mathrm{mV}$ by passing current through the $3 \mathrm{M} \mathrm{KCl-filled} \mathrm{intracellular} \mathrm{recording}$ pipette. Specimen records are presented above the graph. responses was about $200 \mathrm{nM}$ and $100 \%$ antagonism was produced by $10 \mu \mathrm{M}$. The $\mathrm{IC}_{50}$ for bicuculline action was about $1 \mu \mathrm{M}$. Although we employed fewer bicuculline concentrations with cortical neurons (filled circles), a similar dose-dependency was present. Log-log plots of the data (Fig. 5, inset) were linear at low bicuculline concentrations $(<0.8 \mu \mathrm{M})$ but deviated toward the abscissa at higher concentrations. The slope of the linear portion of the $\log -\log$ dose-response curves was 1.0 .

\section{Antagonism of $G A B A$ responses by bicuculline was competitive}

Dose-response curves were obtained for GABA applied by iontophoresis. Such curves were nonhyperbolic, having low response amplitude over the lower GABA iontophoretic charges (current $\times$ duration) and steeply increasing response amplitudes at higher iontophoretic charges (Fig. 6). Maximal GABA responses were not achieved and thus responses were only obtained up to $15-20 \mathrm{mV}$. Log-log plots of GABA dose-response data were linear over low iontophoretic charges but responses deviated toward the current axis at higher charges (Fig. 6,

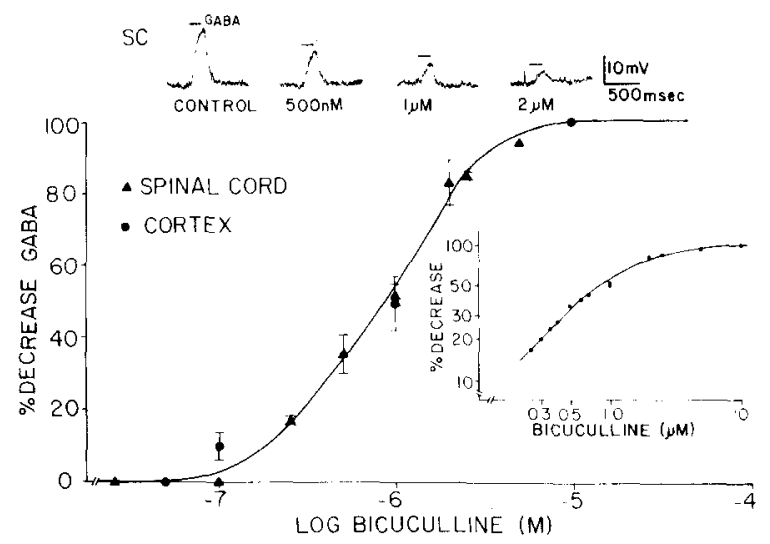

Fig. 5. BICUC inhibition of GABA responses was dosedependent. Superfusion and/or miniperfusion of SC and CTX neurons with BICUC reduced the amplitude of GABA responses evoked by iontophoresis. The percent inhibition of GABA responses obtained from 2-13 SC cells and 3-7 CTX cells at each BICUC concentration tested is plotted with BICUC concentration ( $25 \mathrm{nM}-10 \mu \mathrm{M})$ on the abscissa. Bars indicate \pm S.E.M. Log $\%$ decrease of GABA responses vs $\log$ BICUC concentration is plotted in inset. GABA was applied by constant current pulses of fixed duration (2.4 nA, $125 \mathrm{~ms}$ for data traces above) during application of control and BICUC-containing solutions. Data above were obtained by applying $0,0.5,1.0$, and $2.0 \mu \mathrm{M}$ BICUC. 


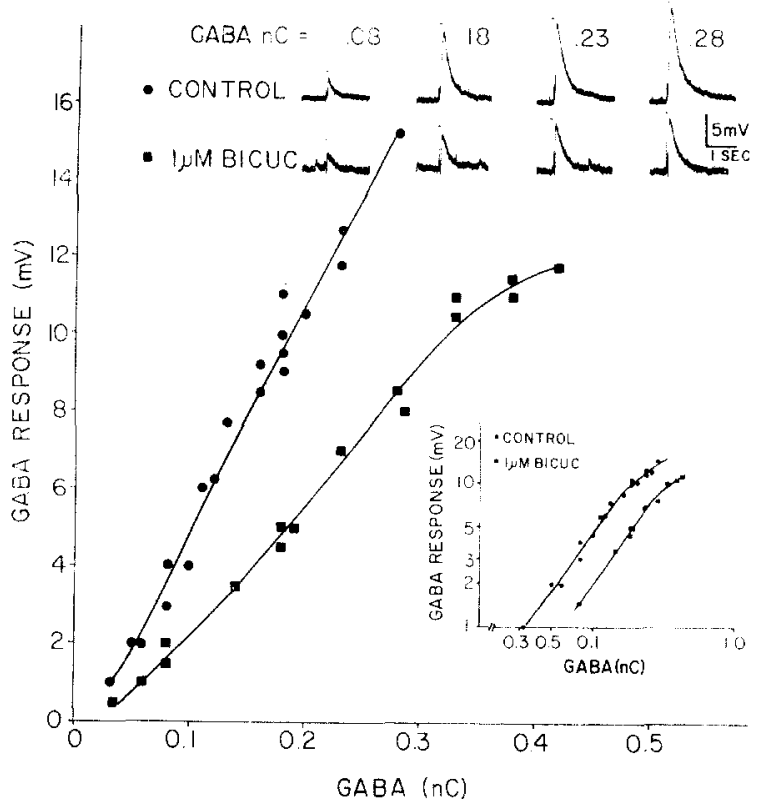

Fig. 6. BICUC altered GABA dose-response curves. GABA dose-response curves were obtained from single $\mathrm{SC}$ neurons in control, and in $1 \mu \mathrm{M}$ BICUC-containing solutions. Medium was changed by superfusion during recording. GABA responses evoked by comparable current pulses were smaller in $1 \mu \mathrm{M}$ BICUC than in control medium (see data traces) resulting in a shift to the right of the GABA dose-response curve. Log GABA response vs log GABA charge is plotted in the inset. RMP was $-57 \mathrm{mV}$ and membrane potential was hyperpolarized to $-80 \mathrm{mV}$ by passing current through the 3 $\mathrm{M} \mathrm{KCl-filled} \mathrm{intracellular} \mathrm{recording} \mathrm{micropipette.}$

inset). The average slope \pm S.E.M. of the $\log -\log$ plots was $1.34 \pm 0.06(n=5)$.

After a dose-response curve was obtained on an individual neuron, bicuculline was superfused into the culture dish, and the dose-response curve was repeated. In the example shown, $1 \mu \mathrm{M}$ bicuculline shifted the GABA dose-response curve to higher GABA charges (Fig. 6) without changing the loglog slope (Fig. 6, inset). Lineweaver-Burke plots made using reciprocals of response and iontophoretic charge were non-linear and did not intersect the ordinate at positive values. However, Lineweaver-Burke plots made using a power function (n $=2$ ) on the abscissa were linear and intersected the ordinate at positive values (Fig. 7). We used the square of the GABA charge since the log-log slope of iontophoretic GABA dose-response data was about 2.0. Bicuculline altered the intercept on the abscissa without changing the intercept on the ordinate. Furthermore, if we used a non-integer power

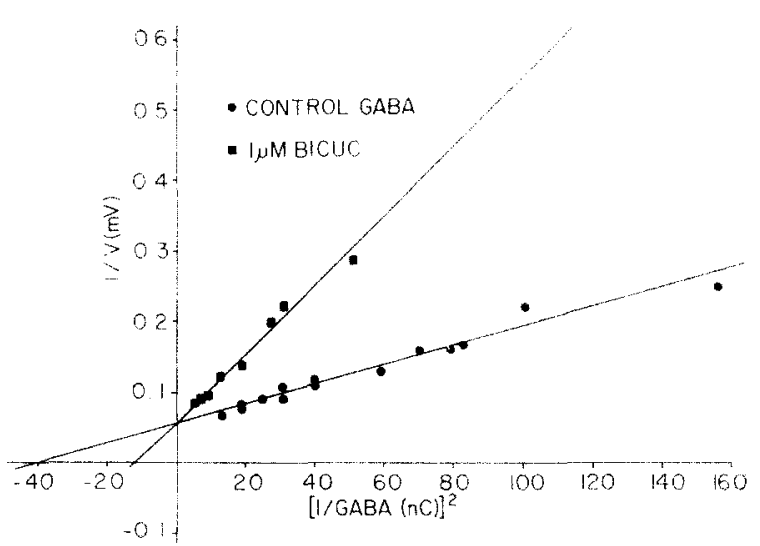

Fig. 7. BICUC antagonism of GABA responses was competitive. The GABA dose-response data in Fig. 6 is replotted as reciprocal of the response amplitude $v$ s the square of the reciprocal of the GABA charge. The apparent $K_{d}$ was shifted without changing the apparent $\mathrm{V}_{\mathrm{max}}$ indicating competitive antagonism.

function on the abscissa to reflect the actual $\log -\log$ slope of the GABA dose-response curve used in the experiment, bicuculline still altered only the abscissa intercept. Therefore bicuculline appeared to antagonize GABA responses competi. tively.

\section{DISCUSSION}

$G A B A$ responses on spinal cord and cortical neurons in cell culture

We have confirmed that GABA produces membrane hyperpolarization of spinal cord ${ }^{2,36}$ and cortical $^{11}$ neurons in primary dissociated cell culture by increasing membrane chloride ion conductance. The dose-dependency of GABA responses evoked on spinal cord neurons in cell culture was similar to that reported for cortical neurons in cell culture ${ }^{11}$ with a threshold of about $1-2 \mu \mathrm{M}$. Sodium-independent $\left[{ }^{3} \mathrm{H}\right] \mathrm{GABA}$ binding demonstrated high and low affinity binding sites on membranes from Triton-treated cortical and spinal cord neurons in cell culture $^{15}$. The potent GABA agonist, $\left[{ }^{3} \mathrm{H}\right]$ muscimol, bound only to high affinity binding sites using Triton-treated membranes suggesting that high affinity binding sites are the relevant sites for postsynaptic GABA responses. The high affinity $\mathrm{GABA}$ binding site had a $K_{d}$ ( $\left.9 \mathrm{nM}\right)$ lower than the threshold concentration of GABA for evoking GABA responses $(2 \mu \mathrm{M})(\text { Fig. } 8)^{15}$. The difference 


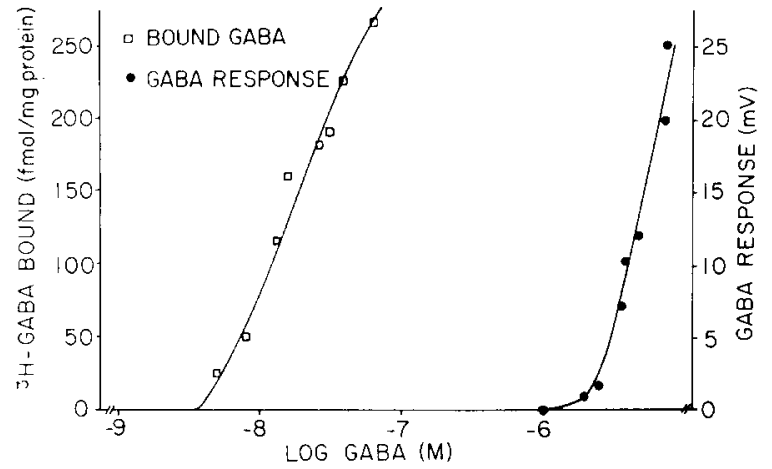

Fig. 8. GABA binding occurred at lower agonist concentrations than GABA responses. Sodium-independent high affinity $\left[{ }^{3} \mathrm{H}\right] \mathrm{GABA}$ binding to Triton-treated membranes from spinal cord neurons in cell culture had a lower $K_{d}(9 \mathrm{nM})$ than the GABA concentration required to evoke threshold GABAresponses $(2 \mu \mathrm{M})$. For details of binding see Fig. 3 of preceding paper ${ }^{15}$ and Fig. 2 of this paper for details of GABA dose-response curve.

in potency for muscimol and GABA in binding studies and for GABA responses may be due to the removal of an inhibitory protein (or other endogenous modulator) by Triton-treatment ${ }^{18,44}$.

When a log-log plot of averaged GABA dose-response data was obtained, the curve was linear at low GABA concentrations $(1-4 \mu \mathrm{M})$ but deviated toward the abscissa at higher concentrations $(>5$ $\mu \mathrm{M})$. The limiting slope of the log-log dose-response curves is an estimate of the Hill number for the agonist receptor interaction ${ }^{47}$. The log-log slope of the average dose-response curve was greater than one (2.8) suggesting that more than one GABA molecule is required at each $\mathrm{GABA}$ receptor to open the GABA-coupled chloride ion channel ${ }^{1,2}$. The slope of the log-log plot of GABA dose-response data obtained for cortical neurons in cell culture was also greater than one (about two) ${ }^{11}$ suggesting that GABA receptors on cortical and spinal cord neurons are organized similarly.

In contrast, saturation studies of $\left[{ }^{3} \mathrm{H}\right]$ muscimol binding in Tritonized spinal cord and cortical membranes were hyperbolic and had Hill numbers of one ${ }^{15}$. Triton treatment of neuronal membranes for binding studies may remove an endogenous inhibitor and alter the kinetics of GABA and muscimol binding to GABA receptors. In addition, receptor desensitization may occur during membrane preparation or during binding experiments where the binding ligand and receptors are in contact for minutes. In the physiological experiments, ligand and receptors are in contact only for seconds. When GABA was applied to spinal cord neurons for longer durations (seconds to minutes), responses to short duration GABA applications $(50 \mathrm{~ms})$ became rounded and diminished in amplitude (Macdonald and Barker, unpublished observation). Furthermore, $\log -\log$ slopes of GABA dose-response curves are reduced to unity. Thus, binding and physiological experiments may not yield equivalent data.

\section{Bicuculline antagonism of $G A B A$ responses}

Bicuculline antagonized GABA responses evoked on cortical and spinal cord neurons at similar concentrations $(0.1-10 \mu \mathrm{M})$. Bicuculline displacement of $\left[{ }^{3} \mathrm{H}\right]$ muscimol from high affinity GABA binding sites was produced over a wider concentration range $(0.1-1000 \mu \mathrm{M})$ but which overlapped the concentration range effective in antagonizing GABA respon$\operatorname{ses}^{15}$. With spinal cord neurons in cell culture, bicuculline antagonized GABA responses with an $\mathrm{IC}_{50}$ of about $1.0 \mu \mathrm{M}$ and displaced specific $\left[{ }^{3} \mathrm{H}\right]-$ muscimol binding with an $\mathrm{IC}_{50}$ of about $10 \mu \mathrm{M}$ (Fig. 9) ${ }^{15}$. With cortical neurons in cell culture, bicuculline also antagonized GABA responses with an $\mathrm{IC}_{50}$ of about $1 \mu \mathrm{M}$ and displaced specific $\left[{ }^{3} \mathrm{H}\right]$ muscimol binding with an $\mathrm{IC}_{50}$ of about $5 \mu \mathrm{M}$ (Fig. 10) ${ }^{15}$.

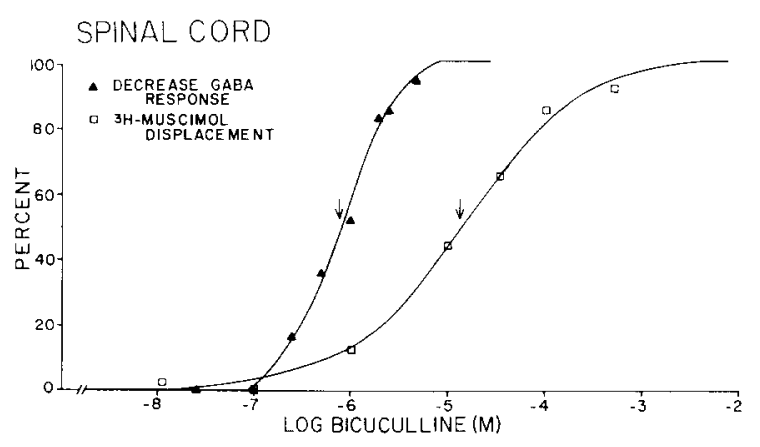

Fig. 9. Spinal cord GABA responses were antagonized at BICUC concentrations which displaced $\left[{ }^{3} \mathrm{H}\right]$ muscimol from spinal cord membranes. BICUC displaced $\left[{ }^{3} \mathrm{H}\right]$ muscimol between $1 \mathrm{nM}$ and $1 \mathrm{mM} \mathrm{BICUC}$ with $50 \%$ displacement at about $10 \mu \mathrm{M}$ BICUC. GABA response amplitude $(10-20 \mathrm{mV})$ was reduced by $0.1-10 \mu \mathrm{M}$ BICUC with $50 \%$ reduction of GABA responses at $1 \mu \mathrm{M}$ BICUC. For details of displacement experiment see Fig. 5 of preceding paper ${ }^{15}$. BICUC antagonism of SC GABA responses is from Fig. 5 of this paper. 


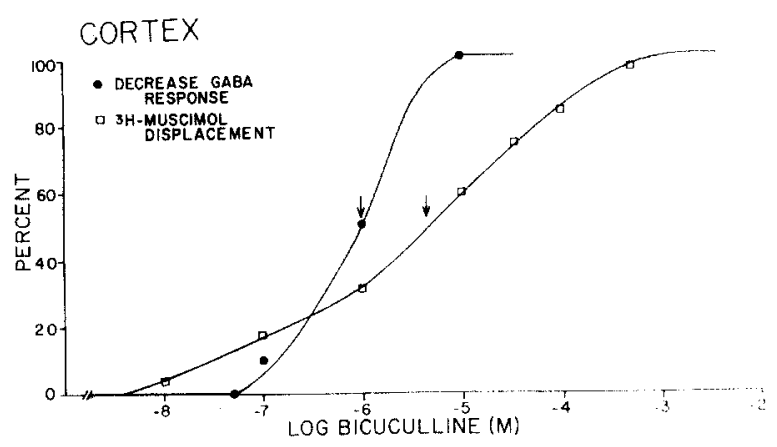

Fig. 10. Cortical GABA responses were antagonized at BICUC concentrations that displaced $\left[{ }^{3} \mathrm{H}\right]$ muscimol from cortical membranes. BICUC displaced $\left[{ }^{3} \mathrm{H}\right]$ muscimol between $1 \mathrm{nM}$ and $1 \mathrm{mM}$ BICUC with $50 \%$ displacement at about $5 \mu \mathrm{M}$ BICUC. GABA response amplitude (10-20 mV) was reduced by $0.1-10 \mu \mathrm{M}$ BICUC with $50 \%$ reduction of GABA responses at $1 \mu \mathrm{M}$ BICUC. For details of displacement experiments see Fig. 5 of preceding paper ${ }^{15}$. Details of reduction of cortical GABA responses are presented in Fig. 5 of this paper.

Thus about $10 \mu \mathrm{M}$ bicuculline will produce a total antagonism of 10-20 mV GABA responses which corresponds to about $50 \%$ and $60 \%$ inhibition of $\left[{ }^{3} \mathrm{H}\right]$ muscimol binding to GABA receptors on spinal cord and cortical neurons respectively. The disparity between $\mathrm{IC}_{50} \mathrm{~s}$ of binding and GABA response antagonism probably reflects a difference in the $K_{i}$ of bicuculline in physiological and binding experimental conditions. In contrast to its inhibition of high affinity $\left[{ }^{3} \mathrm{H}\right] \mathrm{GABA}$ and $\left[{ }^{3} \mathrm{H}\right] \mathrm{muscimol}$ binding, bicuculline displaced low affinity $\left[{ }^{3} \mathrm{H}\right] \mathrm{GABA}$ binding only with high concentrations $\left(K_{i}=115 \mu \mathrm{M}\right)^{15}$. The necessity for such high concentrations of bicuculline for blockade of low affinity binding sites suggests that the low affinity site is not responsible for postsynaptic GABA responses. Furthermore, since bicuculline antagonism of high affinity GABA binding and GABA responses occurs at lower and similar concentrations, it is likely that the high affinity GABA binding site is the site relevant for physiological postsynaptic GABA responses.

On most vertebrate central and peripheral neurons, bicuculline appears to be a competitive inhibitor of GABA responses ${ }^{3,5,25,27,40}$ while on cat dorsal root ganglion neurons ${ }^{16}$ and invertebrate muscle ${ }^{41}$, bicuculline antagonism is noncompetitive or 'mixed' noncompetitive. The antagonism of GABA responses by bicuculline on spinal cord neurons in cell culture could be produced by either competing with GABA for its receptor (competitive inhibition) or by decreasing chloride channel conductance or open time (noncompetitive inhibition). Since bicuculline reduced the amplitude of $\mathrm{GABA}$ responses without altering the time course of GABA responses in the present study, it is likely that bicuculline either competes with GABA for binding to its receptor or decreases channel conductance. To differentiate between these two alternatives, we performed Lineweaver-Burke analysis of GABA dose-response curves with and without bicuculline. Bicuculline altered the apparent $K_{d}$ without affecting the apparent $B_{\max }$ suggesting a competitive interaction between bicuculline and GABA. Similarly, using Scatchard analysis of $\left[{ }^{3} \mathrm{H}\right]$ muscimol binding to rat spinal cord and brain membranes, we have shown that bicuculline antagonism of binding was competitive ${ }^{15}$. Thus both electrophysiological and neurochemical data suggest a competitive interaction between bicuculline and GABA for binding to high affinity GABA binding sites. The log-log plot of the dose-response curve for antagonism of GABA responses by bicuculline was linear at low bicuculline concentrations $(<1 \mu \mathrm{M})$ and had a slope of 1.0. The low inhibitory Hill constant suggests that only one molecule of bicuculline is required to block each GABA receptor.

\section{Multiple GABA-receptors}

In addition to binding to high affinity GABA receptors mediating postsynaptic inhibition, GABA has been demonstrated to enhance the specific binding of $\left[{ }^{3} \mathrm{H}\right]$ benzodiazepines ${ }^{28,43,45}$. However, there are somewhat different structural requirements for enhancing $\left[{ }^{3} \mathrm{H}\right]$ diazepam binding and antagonizing $\left[{ }^{3} \mathrm{H}\right] \mathrm{GABA}$ binding suggesting that there are two distinct types of GABA receptors ${ }^{22}$. Nonetheless, since benzodiazepine receptors and GABA receptors copurify following solubilization ${ }^{17}$, it is likely that the high affinity GABA receptor and benzodiazepine receptor are part of the same macromolecular complex.

What physiological action is produced by activating low affinity GABA receptors? In addition to producing postsynaptic inhibition, GABA decreases release of neurotransmitter from central and peripheral nervous system neurons ${ }^{4}$. The pharmacology 
of presynaptic GABA receptors, however, is quite different from postsynaptic receptors. Presynaptic GABA receptors are insensitive to blockade by bicuculline, poorly bound by muscimol and potently activated by $\beta$-para-chlorophenyl GABA (baclofen $)^{4}$. In contrast, postsynaptic GABA receptors are sensitive to bicuculline, potently activated by muscimol and insensitive to baclofen. Low affinity GABA binding sites are not bound by muscimol and are much less sensitive to bicuculline suggesting that low affinity GABA binding sites may be presynaptic GABA receptors.

\section{REFERENCES}

1 Barker, J. L., Macdonald, R. L. and Smith, T. G., Voltage clamp analysis of amino acid currents in cultured mammalian neurons, J. gen. Physiol., 70 (1977) la.

2 Barker, J. L. and Ransom, B. R., Amino acid pharmacology of mammlian central neurones grown in tissue culture, J. Physiol. (Lond.), 280 (1978)

3 Bowery, N. G. and Brown, D. A., Depolarizing actions of $\gamma$-aminobutyric acid and related compounds on rat superior cervical ganglion in vitro, Brit. J. Pharmacol., 50 (1974) 205-218.

4 Bowery, N. G., Doble, A., Hill, D. R., Hudson, A. L., Shaw, J. S., Turnbull, M. J. and Warrington, R., Bicuculline-insensitive GABA receptors on peripheral autonomic nerve terminals, Europ. J. Pharmacol., 71 (1981) 53-70.

5 Curtis, D. R., Duggan, A. W., Felix, D., Johnston, G. A. R., Bicuculline, an antagonist of GABA and synaptic inhibition in the spinal cord of the cat, Brain Research, 32 (1971) 69-96.

6 Curtis, D. R., Duggan, A. W., Felix, D., Johnston, G. A. R. and McLennan, H., Antagonism between bicuculline and GABA in the cat brain, Brain Research, 33 (1971) 57-73.

7 Curtis, D. R. and Felix, D., The effect of bicuculline upon synaptic inhibition in the cerebral and cerebellar cortices of the cat, Brain Research, 34 (1971) 301-321.

8 Curtis, D. R., Hösli, L., Johnston, G. A. R. and Johnston, I. H., The hyerpolarization of spinal motoneurones by glycine and related amino acids, Exp. Brain Res., 5 (1968) 235-258.

9 Curtis, D. R. and Johnston, G. A. R., Amino acid transmitters in the mammalian central nervous system, Ergebn. Physiol., 69 (1974) 97-188.

10 Deschenes, M., Feltz, P. and Lamour, Y., A model for an estimate in vivo of the ionic basis of presynaptic inhibition: an intracellular analysis of the GABA-induced depolarization in rat dorsal root ganglia, Brain Research, 118 (1976) 486-493.

11 Dichter, M. A., Physiological identification of GABA as the inhibitory transmitter for mammalian cortical neurons in cell culture, Brain Research, 190 (1980) 111-121.

12 Enna, S. J. and Snyder, S. H., Properties of $\gamma$-aminobutyric acid (GABA) receptor binding in rat brain

\section{ACKNOWLEDGEMENTS}

We thank Frank Wilk and Robert Frere for technical assistance and Kathy Lundquist for excellent secretarial assistance. This research was supported by NIH Research Grant NS 15225 to R.L.M. and NS 15140 to A.B.Y. L.M.N. was supported in part by NIMH Training Grant 14279 to the Neurosciences Program. A.B.Y. was supported in part by NIH Teacher Investigator Development Award NS 00420. R.L.M. was supported in part by NIH Research Career Development Award NS 00408.

synaptic membrane fractions, Brain Research, 100 (1975) $81-97$.

13 Enna, S. J. and Snyder, S. H., Influences of ions, enzymes and detergents on $\gamma$-aminobutyric acid-receptor binding in synaptic membranes of rat brain, Molec. Pharmacol., 13 (1977) 442-453.

14 Feltz, P. and Rasminsky, M., A model for the mode of action of GABA on primary afferent terminals: depolarizing effects of GABA applied iontophoretically to neurones of mammalian dorsal root ganglia, Neuropharmacol., 13 (1974) 553-563.

15 Frere, R., Macdonald, R. L. and Young, A. B., GABA binding and bicuculline in spinal cord and cortical membranes from adult rat and from mouse neurons in cell culture, Brain Research, 244 (1982) 145-153.

16 Gallagher, J. P., Higashi, H. and Nishi, S., Characterization and ionic basis of GABA-induced depolarizations recorded in vitro from cat primary afferent neurons, $J$. Physiol. (Lond.), 275 (1978) 263-282.

17 Gavish, M. and Snyder, S. H., $\gamma$-Aminobutyric acid and benzodiazepine receptors: copurification and characterization Proc. nat. Acad. Sci. (U.S.A.), 78 (1981) 1939-1942.

18 Greenlee, D. V., VanNess, P. C. and Olsen, R. W., Endogenous inhibitor of GABA binding in mammalian brain, Life Sci., 22 (1978) 1653-1662.

19 Heyer, E. J., Nowak, L. M. and Macdonald, R. L., Bicuculline: a convulsant with synaptic and nonsynaptic actions, Neurology, 31 (1981) 1381-1390.

20 Homma, S. and Rovainen, C. M., Conductance increases produced by glycine and $\gamma$-aminobutyric acid in lamprey interneurones, J. Physiol. (Lond.), 279 (1978) 231-252.

21 Johnston, G. A. R., Beart, P. M., Curtis, D. R., Game, C. J. A., McCulloch, R. M. and Maclachlan, R. M., Bicuculline methochloride as a GABA antagonist, Nature New Biol., 240 (1972) 219-220.

22 Karobath, M., Placheta, P., Lippitsch, M. and Krogsgaard-Larsen, P., Is stimulation of benzodiazepine receptor binding mediated by a novel GABA receptor? Nature (Lond.), 278 (1979) 748-749.

23 Krnjevic, K., Inhibitory action of GABA and GABAmimetics on vertebrate neurons. In E. Roberts, T. N. Chase and D. B. Tower (Eds.), GABA in Nervous System Function, Raven Press, New York, 1976, pp. 268-281.

24 Krnjevic, K., Chemical nature of synaptic transmission 
in vertebrates, Physiol. Rev., 54 (1974) 418-450.

25 Levy, R. A., The role of GABA in primary afferent depolarization, Progr. Neurobiol., 9 (1977) 211-267.

26 Macdonald, R. L. and Barker, J. L., Specific antagonism of GABA-mediated postsynaptic inhibition in cultured spinal cord neurons: a common mode of convulsant action, Neurology, 28 (1978) 325-330.

27 Martin, R. J., Glycine and GABA induced conductance changes in lamprey reticulospinal neurones and their antagonism by strychnine, thebaine, bicuculline and picrotoxin, Comp. Biochem. Physiol., 63C (1979) 109.

28 Martin, I. L. and Candy, J. M., Facilitation of benzodiazepine binding by sodium chloride and GABA, Neuropharmacol., 17 (1978) 993-998.

29 Möhler, $H$. and Okada, T., GABA receptor binding with ${ }^{3} \mathrm{H}(+)$-bicuculline-methiodide in rat $\mathrm{CNS}$, Nature (Lond.), 267 (1977) 65-67.

30 Nicoll, R. A., The blockade of GABA mediated responses in the frog spinal cord by ammonium ions and furosemide, J. Physiol. (Lond.), 283 (1978) 121-132.

31 Nishi, S., Minota, S. and Karczmar, A. G., Primary afferent neurones: the ionic mechanism of GABA-mediated depolarization, Neuropharmacol., 13 (1974) 215-219.

32 Olsen, R. W., Ban, M., Miller, T. and Johnston, G. A. R., Chemical instability of the GABA antagonist bicuculline under physiological conditions, Brain Research, 98 (1975) 383-387.

33 Olsen, R. W., Ticku, M. K., Van Ness, P. C. and Greenlee, D., Effects of drugs on $\gamma$-aminobutyric acid receptors, uptake, release and synthesis in vitro, Brain Research, 139 (1978) 277-294.

34 Piggott, S. M., Kerkut, G. A. and Walker, R. J., The actions of picrotoxin, strychnine, bicuculline and other convulsants and antagonists on the responses to acetylcholine, glutamic acid and gamma-aminobutyric acid on Helix neurones, Comp. Biochem. Physiol., 57C (1977) 107-116.

35 Pong, S. F. and Graham, L. T., N-Methyl bicuculline, a convulsant more potent than bicuculline, Brain Research, 42 (1972) 486-490.

36 Ransom, B. R., Bullock, P. N. and Nelson, P. G., Mouse spinal cord in cell culture. III. Neuronal chemosensitivity and its relationship to synaptic activity, J. Neurophysiol., 40 (1977) 1163-1177.

37 Ransom, B. R., Neale, E., Henkart, M., Bullock, P. N. and Nelson, P. G., Mouse spinal cord in cell culture. 1.
Morphology and intrinsic neuronal electrophysiologic properties, J. Neurophysiol., 40 (1977) 1132-1150.

38 Roberts, E., $\gamma$-Aminobutyric acid and nervous system function - a perspective, Biochem. Pharmacol., 23 (1974) $2637-2649$

39 Shank, R. P., Pong, S. F., Freeman, A. R. and Graham, L. T., Bicuculline and picrotoxin as antagonists of $\gamma$ aminobutyrate and neuromuscular inhibition in the lobster, Brain Research, 72 (1974) 71-78.

40 Simmonds, M. A., Evidence that bicuculline and picrotoxin act at separate sites to antagonized $\gamma$-aminobutyric acid in rat cuneate nucleus, Neuropharmacol., 19 (1980) 39.45.

41 Smith, T. G. and Constanti, A., A re-examination of the GABA-inhibitory action of bicuculline on lobster muscle, Europ. J. Pharmacol., 70 (1981) 25-33.

42 Takeuchi, A. and Onodera, K., Effect of bicuculline on the GABA receptor of the crayfish neuromuscular junction, Nature New Biol., 236 (1972) 55-56.

43 Tallman, J. F., Thomas, J. W. and Gallagher, D. W., GABAergic modulation of benzodiazepine binding site sensitivity, Nature (Lond.), 274 (1978) 383--385.

44 Toffano, G., Guidotti, A. and Costa, E., Purification of an endogenous protein inhibitor for the high affinity binding of gamma-aminobutyric acid to synaptic membranes of rat brain, Proc. nat, Acad. Sci. (U.S.A.), 75 (1978) 4024-4028.

45 Wastek, G. J., Speth, R. C.. Reisine, T. D., Yamamura, H. I. The effect of $\gamma$-aminobutyric acid on ${ }^{3} \mathrm{H}$-flunitrazepam binding in rat brain, Eirop. J. Pharmacol., 50 (1978) 445-447.

46 Welch, A. D. and Henderson, V. E., A comparative study of hydrastine, bicuculline and adlumine, J. Pharmacol. exp. Ther., 51 (1934) 482-491.

47 Werman, R., An electrophysiological approach to drugreceptor mechanisms, Comp. Biochem. Physiol., 30 (1969) 997-1017.

48 Wong, D. T. and Horng, J. S., Na -independent binding of GABA to the Triton X-100 treated synaptic membranes from cercbellum of rat brain, Life Sci., 20 (1977) 445-452.

49 Zukin, S. R., Young, S. R. and Snyder, S. H., Gammaaminobutyric acid binding to receptor sites in the rat central nervous system, Proc. nat, Acad. Sci. (U.S.A.), 71 (1974) 4802-4807. 